\title{
Screening for Direct Production of Lactic Acid from Rice Starch Waste by Geobacillus stearothermophilus
}

\author{
Balakrishnan Kunasundari ${ }^{1,{ }^{*}}$, Mohamad Faizul Zulkeple ${ }^{1}$, and Yi Peng Teoh ${ }^{1}$ \\ ${ }^{1}$ Faculty of Engineering Technology, Universiti Malaysia Perlis (UniMAP), P.O Box 77, D/A Pejabat \\ Pos Besar Kangar, Perlis, 01000, Malaysia.
}

\begin{abstract}
Lactic acid recently became an important chemical where it is widely used in many industries such as food, cosmetic, chemical and pharmaceutical industry. The present study focuses on the screening for lactic acid production from rice starch waste using a thermophilic amylolytic bacterium, Geobacillus stearothermophilus. There is no information available on direct fermentation of lactic acid from rice starch waste using $G$. stearothermophilus. The effects of different parameters such as temperature, $\mathrm{pH}$, incubation time, agitation speed, concentration of nitrogen and carbon sources on the lactic acid production were assessed. The highest concentration of lactic acid produced was $5.65 \pm 0.07 \mathrm{~g} / \mathrm{L}$ at

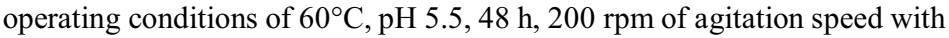
$5 \%$ concentrations of both carbon and nitrogen source. The findings indicated that rice starch waste can be successfully converted to lactic acid by G. stearothermophilus.
\end{abstract}

\section{Introduction}

Lactic acid is considered to be one of the most important chemicals recently where it is widely used in many industries such as food, cosmetic, chemical and pharmaceutical. Besides that, the attraction for using it as a monomer in the manufacture of biodegradable and bio-compatible poly (lactic acid) or PLA has been increasing recently. It is an environmentally friendly and alternative to non-biodegradable plastics which are derived from petrochemicals. The worldwide demand on lactic acid is valued roughly to be around 130000 to 150000 (metric) tonnes per year. A viable approach for production of lactic acid includes fermentation of starch wastes using amylolytic lactic acid producing bacteria [1].

G. stearothermophilus is a thermophilic amylolytic bacterium that can convert starch directly to lactic acid. Most of the lactic acid producing microorganisms require hydrolysis of starch containing carbon sources to glucose before the fermentation process represents an advantage of using this particular bacterium. The other characteristics of this bacterium are facultative anaerobic and gram-positive from the phylum Firmicutes, with an optimum growth temperature between $50^{\circ} \mathrm{C}$ and $60^{\circ} \mathrm{C}$, while $\mathrm{pH}$ of 6.2 and $7.5[2,3]$.

\footnotetext{
* Corresponding author: kunasundari@unimap.edu.my
} 
Rice starch waste was used in this study which can be obtained during washing the rice. The colour of this liquid starch is milky and its texture is non-sticky. This raw material is rarely use by the researchers as the substrate in the fermentation of lactic acid because it is a municipal waste and available in a small volume only. However, when one considers the starch waste from rice industries which would be available in large quantities, then this substrate is an alternative option for production of lactic acid. So far to our knowledge, the potential of rice starch waste to be the substrate for fermentation are not being much investigated. Hence, this study aims to investigate lactic acid production from rice starch waste.

\section{Materials and methods}

Geobacillus stearothermophilus was used throughout this study. Growth profile construction and morphology identification of the bacterium were carried out. Fermentation for lactic acid production was conducted using mineral salt medium with rice starch waste as a sole carbon source by varying the process parameters according to the Plackett-Burman designs. Lactic acid produced from each experiment was quantified using Reflectometer.

\subsection{Growth profile construction}

G. stearothermophilus was maintained on nutrient agar. The culture was prepared by inoculating two loopfuls of the bacterium in $30 \mathrm{~mL}$ Nutrient broth (NB) of a $100 \mathrm{~mL}$ flask. The culture was agitated at $55^{\circ} \mathrm{C}$ and $100 \mathrm{rpm}$ for $24 \mathrm{~h}$. Three mililiter of culture was transferred into $97 \mathrm{~mL}$ of NB in a $250 \mathrm{~mL}$ of flask after $24 \mathrm{~h}$ of incubation time. Optical Density at $600 \mathrm{~nm}\left(\mathrm{OD}_{600 \mathrm{~nm}}\right)$ was determined by sampling at every $3 \mathrm{~h}$ interval for $48 \mathrm{~h}$. At the same time, wet cell weight (WCW) and dry cell weight (DCW) were measured at every sampling point. The growth profile of G. stearothermophilus was plotted based on OD and DCW versus time for each sampling point [4].

\subsection{Morphology identification}

The morphology of the G. stearothermophilus was examined using Gram staining in which it can differentiate bacterial species into two large groups (Gram positive and Gram negative). This classification is based on the chemical and physical properties of bacteria's cell walls [4].

\subsection{Fermentation process}

Lactic acid production was carried in a batch fermentation using $250 \mathrm{~mL}$ flask with working volume of $100 \mathrm{~mL}$. The inoculum was prepared as for growth profile construction and $3 \%$ of culture was transferred into flask containing $97 \mathrm{~mL}$ formulated media with $2 \mathrm{~g} / \mathrm{L} \mathrm{KH}_{2} \mathrm{PO}_{4}, 2$ $\mathrm{g} / \mathrm{L} \mathrm{NaCl}, 0.2 \mathrm{~g} / \mathrm{L} \mathrm{MgSO}_{4}, 0.05 \mathrm{~g} / \mathrm{L} \mathrm{MnSO}_{4}, 0.01 \mathrm{~g} / \mathrm{L} \mathrm{FeS0}_{4} .7 \mathrm{H}_{2} 0$ and $12 \mathrm{~g} / \mathrm{L}$ of $\mathrm{CaCO}_{3}$. The amount of rice starch waste and yeast extract were varied according to the screening experiments. All experiments were conducted in triplicate to examine reproducibility and the average values are reported. 


\subsection{Lactic acid quantification}

The analysis of fermentation product in this study was determined using Reflectometer. This equipment is functioned to detect the quantity of lactic acid that was produced. The sample strip was dipped into the fermented culture for 2 seconds before it was dried with filter paper. The presence of lactic acid was indicated when the colour of the sample strip turned purple from white. The detection time for each sample took 5 minutes to complete. The result was displayed on the screen of the equipment. The maximum concentration that can be detected by LA kit was $60 \mathrm{mg} / \mathrm{l}$ and the reading. Dilution was required for concentration of sample above that limit.

\subsection{Screening for lactic acid production at various process parameters conditions}

The Design-Expert ${ }^{\circledR}$ Version 7.1.5 software was used in this study for designing procedure of the Response Surface Methodology as shown in Table 1. By employing Plackett-Burman designs, different temperature, incubation time, $\mathrm{pH}$, agitation speed, and different concentrations of carbon and nitrogen source were analyzed.

Table 1. Screening of the parameters using Plackett-Burman designs.

\begin{tabular}{|l|c|c|c|c|c|c|}
\hline Run & Factor 1 (A) & Factor 2 (B) & $\begin{array}{c}\text { Factor 3 } \\
(\mathrm{C}) \\
\text { Time (h) }\end{array}$ & $\begin{array}{c}\text { Factor 4 (D) } \\
\text { Agitation } \\
(\mathrm{rpm})\end{array}$ & $\begin{array}{c}\text { Factor 5 (E) } \\
\text { Carbon } \\
\text { source }\end{array}$ & $\begin{array}{c}\text { Factor 6 (F) } \\
\text { Nitrogen } \\
\text { source }\end{array}$ \\
\hline 1 & 50 & 5.5 & 24 & 200 & 1 & 10 \\
\hline 2 & 60 & 7.5 & 24 & 200 & 5 & 10 \\
\hline 3 & 60 & 7.5 & 24 & 100 & 1 & 10 \\
\hline 4 & 60 & 5.5 & 24 & 100 & 5 & 5 \\
\hline 5 & 60 & 5.5 & 48 & 200 & 5 & 5 \\
\hline 6 & 60 & 5.5 & 48 & 200 & 1 & 10 \\
\hline 7 & 50 & 7.5 & 48 & 100 & 5 & 10 \\
\hline 8 & 50 & 5.5 & 24 & 100 & 1 & 5 \\
\hline 9 & 60 & 7.5 & 48 & 100 & 1 & 5 \\
\hline 10 & 50 & 7.5 & 48 & 200 & 1 & 5 \\
\hline 11 & 50 & 7.5 & 24 & 200 & 5 & 5 \\
\hline 12 & 50 & 5.5 & 48 & 100 & 5 & 10 \\
\hline
\end{tabular}

\section{Results and discussion}

G. stearothermophilus is a thermophilic bacterium that can convert starch directly to lactic acid due to ability to produce $\alpha$-amylase. Previously, the bacterium has been reported to produce lactic acid yield up to $81.2 \%$ when potato residues from food processing was used as a carbon source [2]. The present study focusing on the utilization of rice starch waste as an alternative substrate for potato waste. The growth profile was plotted in order to ensure the subsequent fermentation experiments were carried out using culture in log phase. The screening experiments at different process paramaters are important to determine the conditions that maximize the lactic acid production from rice starch waste by $G$. stearothermophilus. 


\subsection{Construction of growth profile}

Figure 1 shows the growth profile of $G$. stearothermophilus where the optical density readings started to increase dramatically from 9 up to $27 \mathrm{~h}$ of incubation time. The increase in OD reading indicates that the cells were in exponential phase. The culture in this phase was used as inoculum for lactic acid experiments. After $27 \mathrm{~h}$ of incubation time, the OD reading at $600 \mathrm{~nm}$ started to decline until $48 \mathrm{~h}$. This indicated that the dead cells of $G$. stearothermophilus were accumulating in the culture broth. Hence, culture incubated for more than $27 \mathrm{~h}$ was not suitable to be used as inoculum for fermentation process involving lactic acid production because the cell has reached its death stage.

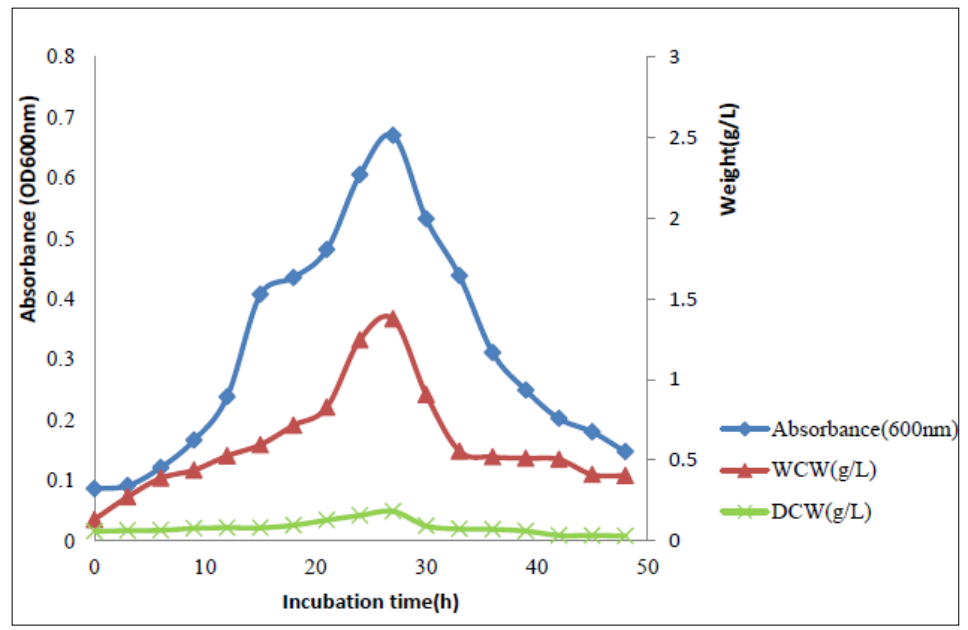

Fig. 1. Optical density $\left(\mathrm{OD}_{600 \mathrm{~nm}}\right)$, Wet cell weight $(\mathrm{WCW})$ and Dry cell weight $(\mathrm{DCW})$ versus incubation time for $48 \mathrm{~h}$ at $55^{\circ} \mathrm{C}$ and $100 \mathrm{rpm}$.

\subsection{Determination of G. stearothermophilus morphology}

Literature search indicating that G. stearothermophilus is a rod-shaped, Gram-positive, spore-forming bacterium that able to grow either singly or in chains [2]. A Gram staining method was conducted followed by observation of the culture under the microscope.In general, the bacterium was found to be in rod-shape (Figure 2[A], [B] and [C] and staining procedure showed that it belongs to Gram-positive as reported previously [2]. Observation revealed the changes in cell morphology with increasing incubation time from $0 \mathrm{~h}$ to $48 \mathrm{~h}$. At $0 \mathrm{~h}$ (Figure $2[\mathrm{~A}]$ ), the culture was determined to be shorther in size when compared to $9 \mathrm{~h}$ and $27 \mathrm{~h}$ (Figure $2[\mathrm{~B}]$ and $[\mathrm{C}]$ ). This is because the culture was in lag phase and required time to adapt to the growth medium. The culture was found to be longer in size at $9 \mathrm{~h}$ and 27 $\mathrm{h}$ while dispersed well in the medium which indicated they were in log phase. The bacterium was actively growing while the nutrients from the growth medium have been rapidly utilized. When the incubation time was increased to $48 \mathrm{~h}$ (Figure 2 [D]), the bacterial cells were observed to clump together which clearly pointing the culture were in death phase. The depletion of nutrients and the accumulation of metabolic waste products are the main reasons for the decline in the culture growth at $48 \mathrm{~h}$. 


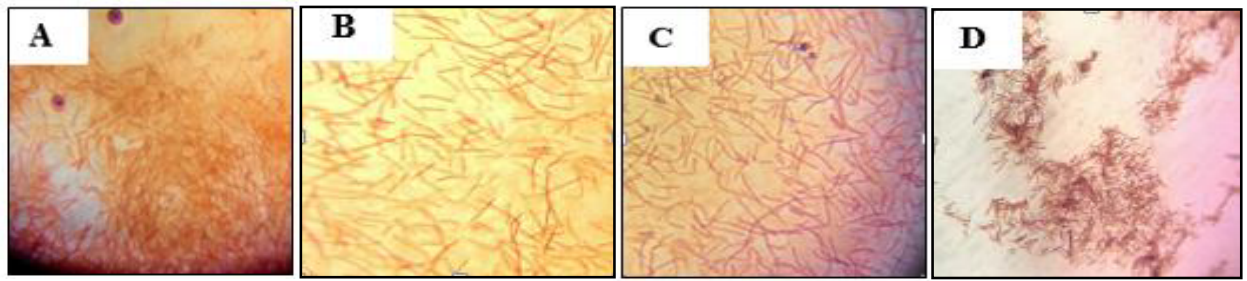

Fig. 2. Morphologies of Geobacillus stearothermophilus at [A] 0 h, [B] 9 h, [C] 27 h and [D] $48 \mathrm{~h}$.

\subsection{Screening for lactic acid production at various process parameters conditions.}

The variation on concentrations of lactic acid were determined by the parameters used for each run. In total, there was 6 parameters tested and for each run the parameters was varied within specific range. From the result (Figure 3), run no.5 has produced highest concentration of lactic acid followed by run no. 2 which was $5.65 \pm 0.07 \mathrm{~g} / \mathrm{L}$ and $5.33 \pm 0.49$ $\mathrm{g} / \mathrm{L}$ respectively. Meanwhile, run no. 8 that produced the lowest concentration of lactic acid with $0.75 \pm 0.21 \mathrm{~g} / \mathrm{L}$. Run no. 5 that produced highest lactic acid concentration was conducted at $60^{\circ} \mathrm{C}, \mathrm{pH} 5.5,48 \mathrm{~h}$ of incubation, agitated at $200 \mathrm{rpm}, 5 \%$ of carbon and nitrogen source concentrations. The second highest was run no. 2 which conducted with temperature at $60^{\circ} \mathrm{C}$, $\mathrm{pH} 7.5,24 \mathrm{~h}$ agitated at $200 \mathrm{rpm}, 5 \%$ of carbon source concentration and $10 \%$ nitrogen source concentration. It was reported that $37 \mathrm{~g} / \mathrm{L}$ lactic acid was obtained in $20 \mathrm{~h}$ at $60^{\circ} \mathrm{C}$ using the same bacterium $G$. stearothermophilus when potato starch was used as a carbon source [2]. Our findings clearly demonstrated the potential of rice starch waste as a substrate and ability of G. stearothermophilus to convert this waste directly into lactic acid which is not the common feature of most of the lactic acid producers.

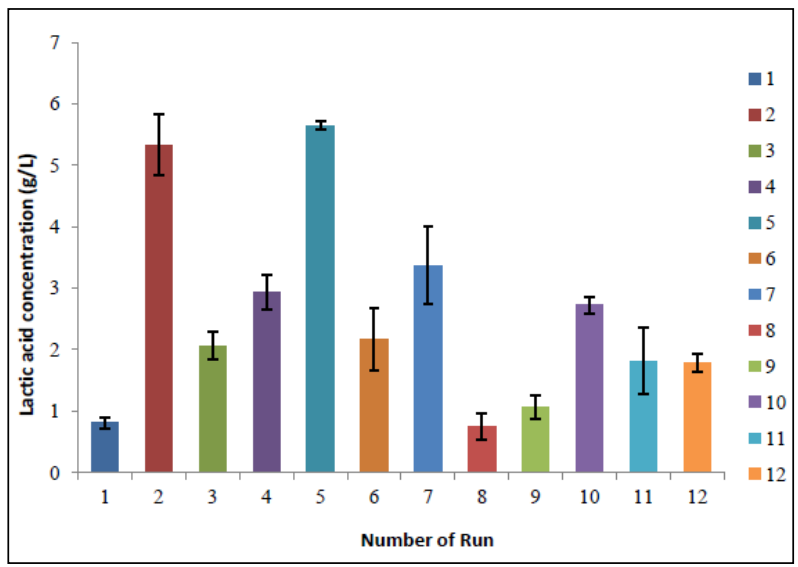

Fig. 3. Lactic acid concentration in each run.

\subsection{Response Surface Methodology}

The response surface methodology was used to evaluate the effects of the parameters that have been tested in this study. The three-dimensional plot is a graphical analysis of regression equation to analyze the optimum condition within the range that resulted in optimum response. The relationship between the response and the variables was envisioned by response surface developed concurring of two test variables. The effect of the temperature and concentration of carbon on the production of lactic acid from rice starch waste was shown in Figure 4 for 3-D surface. It shows a clear peak from 3-D response surface plot from the effect of temperature and concentration of carbon source. The peak for temperature was 
located at the area of $57.50^{\circ} \mathrm{C}$ to $60.00^{\circ} \mathrm{C}$ while 4.5 to $5 \%$ for carbon source. The 3 -D graph demonstrates that the production of lactic acid increased gradually as the temperature increases up to $60^{\circ} \mathrm{C}$ while at the same time dependent on the concentration of carbon in the range 4 to $5 \%$. An increased in temperature above $60^{\circ} \mathrm{C}$ and carbon source above $5 \%$ concentration did not effects the lactic acid production since the activity of the bacterium has stopped due to inactivation of the bacterial cells above its optimal temperature. In conclusion, DOE software was able to identify the variables that were significant for the production of lactic acid which was the temperature and carbon source concentration.

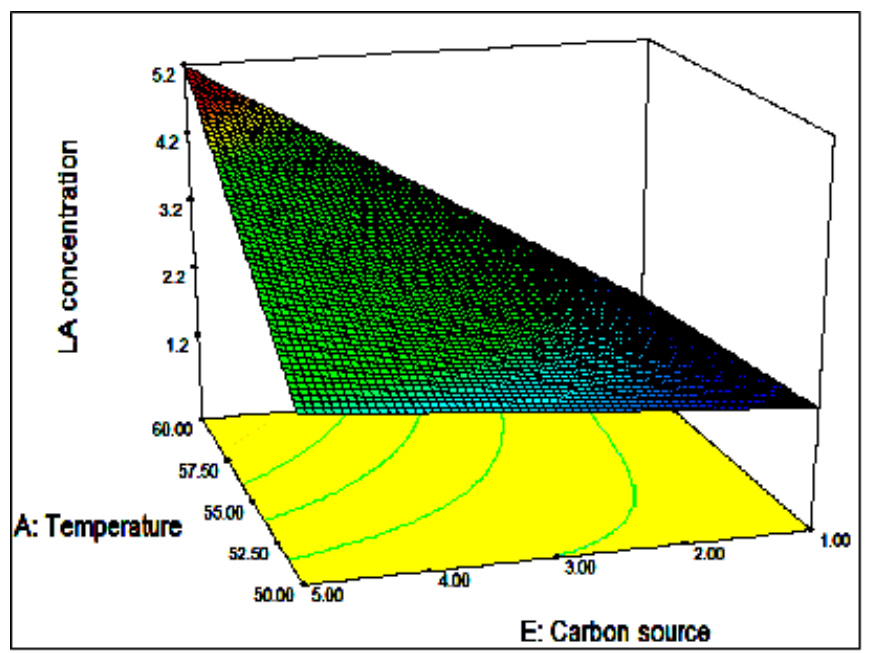

Fig. 4. The 3-D plot of temperature and carbon source interaction.

\section{Conclusion}

The six parameters was screened using Plackett-Burman design and there was 12 run in total for fermentation. From the result obtained, run no.5 showed the highest lactic acid concentration and followed by run no.2 with $5.65 \pm 0.07$ and $5.33 \pm 0.49$ respectively. However, further detail research on the optimization of lactic acid production by $G$. stearothermophilus using rice starch waste is important to prove it is an economically viable carbon source.

This study was supported by Fundamental Research Grant Scheme (FRGS), Grant No: 9003-00530[FRGS/1/2015/SG05/UNIMAP/02/4] entitled: Identification of New Cellulolytic Bacterial Strains from Tropical Mangrove Soil.

\section{References}

1. R. Palaniraj, P. Nagarajan, Int. J. ChemTech. Res., 4, 1049, (2012)

2. M. Smerilli, M. Neureiter, S. Wurz, C. Haas, S. Fruhauf, W. Fuchs, J. Chem. Technol. Biotechnol., 1, (2015)

3. I. Pagana, R. Morawicki, T.J. Hager, J. Food. Sci. Tech., 49, 641, (2013)

4. A.O Buyukkileci, S. Harsa, J. Chem. Technol. Biotechnol., 79, 1036, (2004) 